\title{
Setting up the Recreational Experience Scale for the Individual and Team Sports Players "Dr/Mohamed Ibrahim Al-Zahaby
} Abstract

This research aims at setting up the recreational experience scale for the individual and team sports players in the Arab Republic of Egypt. The researcher used the descriptive methodology where the research sample covered 337 players who practice the recreational activities. They were selected using the perpendicular method from the following governorates (Cairo, Alexandria, Dakhalia, Gharbia, Sharkia, Minya, Sohaj and Asuit). The researcher used the recreational experience scale (prepared by the researcher) as a tool for data collection.

This research results are as follows: The recreational experience scale from (37) individuals distributed over (7) dimensions. The recreational experience scale was characterized of high steadiness and a high level of recreational experience for the individual and team sports players. The older and more experienced players practice the recreational activities which aim at getting a better health and a more active life. The individual and team sports players realize that achieving a personal balance from the body and mental aspects.

\section{Among the important recommendations:}

Utilizing the current scale in identifying the recreational experience level for individual and team sports players. The continuity of practicing the recreational activities in parallel with the training and competition periods, Implementing the recreational experience scale on various categories from the Arab society.

Key words: Recreational Experience, Individual and Team Sports Players

\section{Introduction \& Research Problem}

The desire to contribute in the recreational activities as considered as one of the practices which implies the

formation of the individuals and which is related to them and their lives. Hence, the developed countries paid much

* Assistant professor at sport recreation dep., faculty of physical education, Mansoura university of Egypt 
attention to these recreational activities as they realize that these are the best investment of their spare time where there is a close correlation between the spare time and the recreational activities i.e. the more spare time the greater is the need for practicing the promotional activities.

Solaieman \& Saeid (2004) stated that the spare time policy in the contemporary societies is based on a humanitarian principle which aims at converting the spare time into recreational activities which match the individuals' trends. The spare time depends on the nature of various activities practiced by the individuals in their daily lives where they are chosen with their free will which match their inclinations and their social and psychological nature to be exploited positively (18: 154).

Therefore, practicing the recreational activities make the players gain much information which grants rich dimensions for the personality which promotes the recreational awareness required for the effective participation. The more knowledge and concepts gained by the player towards a certain activity, the more the opportunities of his participating in it.

Kadoury (2015) stated that practicing the recreational activities is closely correlated to the awareness i.e. the intact mind exists with the intact body. The sports strengthen the body and the awareness has its role in enlightening and activating the mental state where the knowledge which accompanies the recreational activities are among the important factors which affect the player's behavior where he will select those promotional sports activities which are most suitable for his potentials and inclinations (11: 9).

The recreational activities play a role in preparing the players through providing them with several skills which enable them to adapt to the society and making them acquire some various values and benefits. Therefore, the trainers have to discover the inclinations and the level of potentials and study the needs considering previous experience where this action 
will help in gaining new experience and achieves the correlation between the old and new e xperience.

Al-Hamahmy \& Abd AlAziz (2009) stated that the participation in the recreational activities teaches the motional skills for various games and sports where these motional activities are characterized of their continuity and the promotion in the standard of performance (2: 91).

Talba (2010) points out that the trend is an important process for the social bearing up. It cares about the formation of trends towards attitudes which correlates to practicing the spare time activities along the age stages (19: 317).

Al-Samnodi \& Others(2017) stated that the recreational activities helps in making the players acquire various skills which include: the social adaptation with others; developing the humanitarian relations; developing the communications skills and practicing the social and democratic life (3: 91).
The researcher recommends that practicing the recreational activities helps in: relaxation; developing the personality; developing the right social relations and developing the positive trends towards the various activities. The recreational activities also aim at developing positive trends towards various activities which are considered by the players as an important role towards their personalities. They also help to adapt tothe society and provide them the ability to take decisions in the psychological situations through independent thinking. Recent years witnessed an increasing attention given by various scientists especially in practicing various activities, not for the purpose of competition, but as a type of protection and treatment from the diseases and the psychological diseases resulted from the daily life pressures in the light of the fast technological advances witnessed by the world. This attention is resulted from the results of the studies which showed that most of the society categories don't practice 
sufficient activities to achieve a more active life due to the little mobility resulted from the modern technological discoveries which offer them comfort in their public life. nervous and psychological pressures results in many problems which have negative reflections which result in feeling very anxious at the sports levels and on the scope of progress in the skills and the desire to win and scaring defeat.

Looking through many scientific sources, it became clear for the researcher that the Arabic libraries lack the scientific and technical measures which covers the recreational expertise. He also noticed the non-existence of a measure for the recreational expertise had an importance in knowing the awareness of the players of how to invest in their spare time to cause equilibrium between their public life and their sporting life and to limit their imposition to psychological pressures such as the consequences of the competition and training.

Research aim:

This research aims at setting up the recreational experience scale for the individual and Team sports players in Arab Republic of Egypt.

\section{Research Questions:}

- What are the constitutes of the recreational experience scale for the individual \& Team sports players?

- What The scope of validity of the recreational experience scale for the individual \& team sports players?

- What are the estimated standards used for recreational experience scale for the individual and team sports players?

- What are the statistical significance between the averages responses of the individual and team sports players in the recreational experience according to the variables (Age, type of game, experience in the sport, amount of daily spare time and the practiced activities)?

\section{Definitions of some of} Research Terms:

The Recreational Experience: This is defined by the researcher as a group of information, skills and trends which are gained by the players as the consequence of repeated practice for the various optional activities during his spare time. 
The Research Plan \& Procedures:

\section{Research Methodology:}

The researcher used the descriptive methodology with its steps and procedures.

\section{Research Sample \& Population:}

The research population consisted of the experienced sports teams players individual and collective sports - who were registered with various Egyptian Unions for the sports season (2016 2017).

The researcher tested the research sample using the perpendicular method. This sample consisted of players who are experienced in recreational activities where their numbers equal 337 players from the governorates (Cairo, Giza, Alexandria, Dakhalia, Gharbia, Sharkia, Minya, Sohaj and Assuit) (Appendix A).

This sample included players from various age groups who have spare time, training ages, practitioners of various sports and recreational activities Appendix (B)

Data Collection Tool:
The researcher used the recreational experience measure (prepared by the researcher) (Appendix C)

The Exploratory Study: The researcher implemented the exploratory study on a sample consisting of (50) players from inside and outside the research population during the period $(1 / 2 / 2017)$ to $(15 / 2 / 2017)$. The study aimed at defining the clarity of the instructions related to data collection tool and the suitability of formulating the items to the sample understanding level to reach the final form. The research results clarification of the instructions and suitability of formulating some items to the level of understanding the sample .

\section{The Main Study:}

Data collection tool was implemented over the period from (1/3/2017) until (15/4/2017). Having finished the process of implementation, the data were collected, organized and tabulated to perform the statistical analysis.

\section{The Used Statistical Methods:}

The researcher used the statistical package SPSS for the following statistical methods: Arithmetical Average, Standard 
Percentage, Pearson Simple Correlation ${ }^{\circledR}$, Alpha Cronbach Coefficient, Amended degree, two-sample statistical significance (t-test), statistical differences for the test samples(F).

Presentation, Explanation \& Discussing the Results:
To achieve the research aim and to answer the questions within the limits of the research sample and methodology, the researcher presents his results classified as follows:

- The components of the recreational experience measure for the individual and team sports players

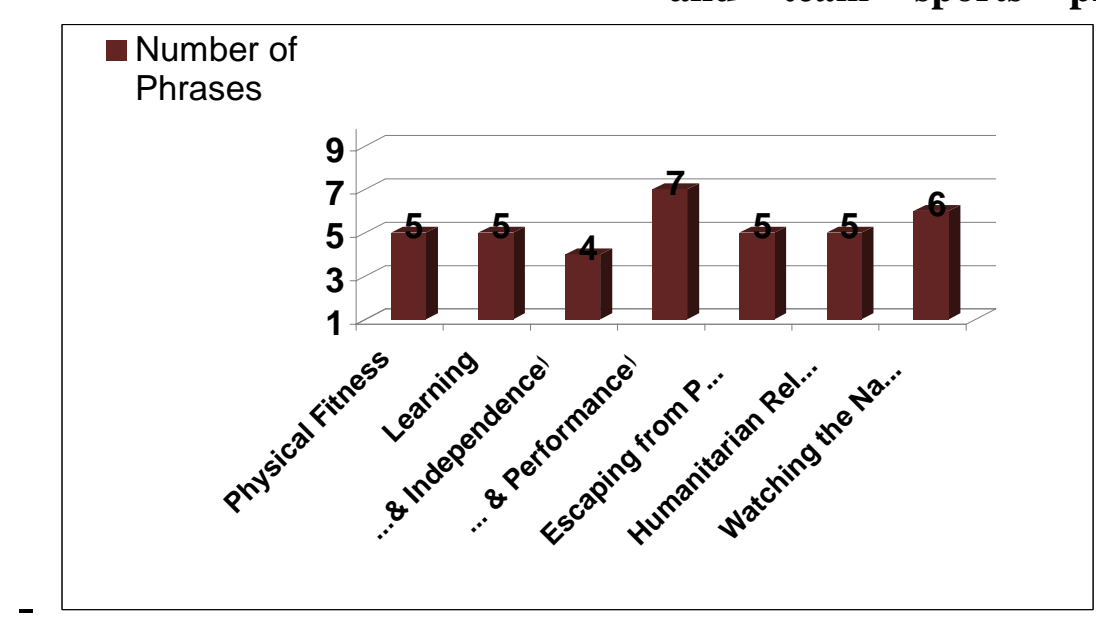

Figure (1) Number of the Measure Phrases in its final form

Figure (1) shows: recreational experience scale consists of (7) dimensions consisting of (37) items in the final form.

- Validity of the recreational experience scale for the individual and team sports and games players.

Validity of the Recreational Experience Scale:The researcher used validity of the contents and setup to scale the validity of the measure as follows:

-Validity of the Contents: This means the scope of representing and correlating the measure components (dimensions - items) using the side which it measures. This is done through referring to the specialized scientific references to guarantee 
achieving the local setup of the contents and implication of the measure.

-Validity of the setup: The pointers of validity of the setup follows the statistical procedures to analyze and differentiate the phrases such as:

-The Extremist Groups: Through finding the differences between the scale sides in the group with the high direction and the group with lower direction using (91) individuals at $(27 \%)$ for each group. Then calculating the value of t-test and the $\mathrm{d}$ istinctivephrases which obtained a calculated value of (1.96) or more which has a statistical significance at $(0.05)$ Level and a Degree of Freedom (180). As shown in. (Appendix D)

-Validity of the Internal Coordination: Through finding the Coefficient of Correlation between the degrees of each phrase with the total degree for the axis which it represents and the total degree for the measure and the coefficients of correlation which are statistically significant at (0.05) Level and Degree of Freedom equals.

Steadiness of the Recreational Experience Scale: The researcher used the method of division and Alpha Cronbach Coefficient to measure the validity of the scale as follows:

-Method of Retailing: Through calculating the value of Sperman-Brown equation and the correction equation by Guttman through dividing the phrases into upper and lower halves. The steadiness coefficient in Sperman Brown equation equals (0.725) and in Guttman equation equals (0.724) where this value is considered as a strong indicator.

- CronbachAlpha Coefficient: Through calculating this coefficient's value which depends on the coordination of the examined performance from one phrase to another. The Coefficient of Steadiness equals $(0.731)$ where this value is considered as a good indicator.

The Standard Error for the Recreational Experience Scale: The researcher used the standard error to measure the 
validity and accuracy of the scale. The lower the value of the standard error, the greater the accuracy in the degrees of scale. The Arithmetic Average equals (97.49) with a Standard Deviation equals (8.806). The Standard Error equals (0.48) i.e. if the player got Grade (S) I the measure, then its degree grade will be after adding or substracting of $\left(0.48^{\circ}\right)$.
The Standards and the Estimated Levels used to scale the Recreational Experience for the Individual \& Team Sports Players:

-The Standards: The researcher converted the raw degrees to standard grades followed by adjusted standard grades to express the raw grade considering the position of the relative player in his standard group.

\section{Table (1)}

\section{Z-Score, T-Score of the Research Sample in recreational} experience scale

\begin{tabular}{c|c|c|c|c|c|c|c|c|c}
\hline \hline $\mathbf{N}$ & $\begin{array}{c}\text { Z- } \\
\text { Score }\end{array}$ & $\begin{array}{c}\text { T- } \\
\text { Score }\end{array}$ & Frequency & $\begin{array}{c}\text { Cumulative } \\
\text { Percent }\end{array}$ & $\mathbf{N}$ & $\begin{array}{c}\text { Z- } \\
\text { Score }\end{array}$ & $\begin{array}{c}\text { T- } \\
\text { Score }\end{array}$ & Frequency & $\begin{array}{c}\text { Cumulative } \\
\text { Percent }\end{array}$ \\
\hline \hline 59 & -4.37 & 6.289 & 1 & 0.30 & 93 & -0.51 & 44.89 & 11 & 26.10 \\
\hline 73 & -2.78 & 22.19 & 2 & 0.90 & 94 & -0.39 & 46.03 & 16 & 30.90 \\
\hline 74 & -2.67 & 23.32 & 3 & 1.80 & 95 & -0.28 & 47.17 & 7 & 32.90 \\
\hline 75 & -2.55 & 24.46 & 2 & 2.40 & 96 & -0.17 & 48.30 & 12 & 36.50 \\
\hline 76 & -2.44 & 25.59 & 2 & 3.00 & 97 & -0.05 & 49.44 & 17 & 41.50 \\
\hline 77 & -2.33 & 26.73 & 2 & 3.60 & 98 & 0.06 & 50.58 & 17 & 46.60 \\
\hline 78 & -2.21 & 27.86 & 2 & 4.20 & 99 & 0.17 & 51.71 & 14 & 50.70 \\
\hline 79 & -2.09 & 29.00 & 7 & 6.20 & 100 & 0.28 & 52.85 & 14 & 54.90 \\
\hline 80 & -1.99 & 30.13 & 3 & 7.10 & 101 & 0.39 & 53.98 & 25 & 62.30 \\
\hline 81 & -1.87 & 31.27 & 1 & 7.40 & 102 & 0.51 & 55.11 & 18 & 67.70 \\
\hline 82 & -1.75 & 32.41 & 3 & 8.30 & 103 & 0.62 & 56.25 & 20 & 73.60 \\
\hline 83 & -1.64 & 33.54 & 4 & 9.50 & 104 & 0.74 & 57.39 & 13 & 77.40 \\
\hline 84 & -1.53 & 34.68 & 1 & 9.80 & 105 & 0.85 & 58.52 & 22 & 84.00 \\
\hline 85 & -1.42 & 35.81 & 3 & 10.70 & 106 & 0.97 & 59.66 & 13 & 87.80 \\
\hline 86 & -1.30 & 36.95 & 5 & 12.20 & 107 & 1.08 & 60.79 & 9 & 90.50 \\
\hline 87 & -1.19 & 38.08 & 4 & 13.40 & 108 & 1.19 & 61.93 & 10 & 93.50 \\
\hline 88 & -1.08 & 39.22 & 4 & 14.50 & 109 & 1.31 & 63.06 & 16 & 98.20 \\
\hline 89 & -0.96 & 40.35 & 3 & 15.40 & 110 & 1.42 & 64.20 & 5 & 99.70 \\
\hline 90 & -0.85 & 41.49 & 9 & 18.10 & 111 & 1.53 & 65.34 & 1 & 100.00 \\
\hline 91 & -0.74 & 42.63 & 8 & 20.50 & & & & & \\
\hline 92 & -0.62 & 43.76 & 8 & 22.80 & Total & 0.00 & & 337 & \\
\hline \hline & & & & & & & & & \\
\hline
\end{tabular}


The Estimated Levels:

The researcher introduced estimated levels to judge the player's grades in the recreational experience scale.
The estimated level for the responses of the research sample was high as shown in Table (2).

Table (2)

Estimated level of the Research Sample in recreational experience scale

\begin{tabular}{c|c|c|c|c}
\hline \hline $\mathbf{N}$ & Frequency & Percent & $\begin{array}{c}\text { Cumulative } \\
\text { Percent }\end{array}$ & $\begin{array}{c}\text { Estimated } \\
\text { level }\end{array}$ \\
\hline \hline 37: 59 & 0 & 0.00 & 0.00 & Very low \\
\hline$+59: 72$ & 1 & 0.30 & 0.30 & Low \\
\hline$+72: 85$ & 32 & 9.50 & 9.80 & Middle level \\
\hline$+85: 98$ & 120 & 35.60 & 45.40 & High \\
\hline$+98: 111$ & 184 & 54.60 & 100.00 & Very high \\
\hline 37: 111 & 337 & 100.00 & & High \\
\hline \hline
\end{tabular}

Difference among the response rate in individual and team sport players in recreational experience according to(Age, type of game, experience in the sport, amount of daily spare time and the practiced activities) (Appendix E)

Table (3) shows that: there are statistically significant differences in (Physical Fitness) dimension among players who are less or equal (25) years old in favor of more than (25) years where the value of the calculated (T) value is greater than its tabular value at (0.05) level. This is due to their knowledge of the importance of practicing the recreational activities during spare time in order to acquire physical fitness so that they reach a better life and reduces the probability of having heart and obesity diseases as the consequence of low mobility resulted from using the modern technological inventions. This matches with the results of Chih,Y and Feng,H (2016) (4) study which showed that practicing the recreational activities make the individuals gain the physical fitness The Jeroen,S and Steven, V (2016) (5) study showed that seven out 
of ten individual practice the sport as a physical activity during their spare time.

There are also: statistically significant differences in the (Learning, Performance \& Incentive) parameters among the players who are less than (25) years and more than (25) years in favor of those who are less than (25) years where the value of calculated (T) value is greater than its tabular value at (0.05) level. This is due to their desire in the research for truth and learning many things where practicing recreational activities have a great positive role in providing new cultures and various opportunities. This matches with Meryem,A \& Ece,D study (2016) (10) study which showed that participating in the recreational activities results in increasing the acquired experiences gained from learning. The results of Kubra,A \& Murat (2013) (7) study showed that The motive of participation is nglearning and achievi

Table (4) shows that: there are a statistically significant differences in the (Physical Fitness, Escaping from Personal, Psychic \& Social Pressures) dimensions among players less than (10) years and more than (10) years in practicing the sport in favor of (10) year and more where the value of calculated $(\mathrm{T})$ is greater than its tabular value at (0.05) level. This is due to their having experience as the consequence of their repeated participation with the optional activities which contributes in obtaining and preserving a suitable level of physical fitness and getting rid of exhaustion and mental tiredness and getting the psychic equilibrium. These results match with the results of Feng, H .Chih,Y (2016) (4) study which showed that practicing the recreational activities improves the physical fitness and reduces tension and relaxation.

There also non statistically significant differences in the (Learning, independence, leadership, performance, incentive, humanitarian relations \& viewing the nature) dimensions among players who are less than (10) years and more than (10) years in practicing sports 
where value of calculated $(\mathrm{T})$ is less than its tabular value at (0.05) level. This is because all players wanted to gain the recreational awareness required to participate in various activities where the better the player's knowledge towards a certain activity, the opportunity for participation in it increases and achieves a better standard in performance. Also, investing the spare time during the training camps in enjoying the fresh air and developing the acoustic taste and developing the spiritual values and activating the familial collective life. All this match with results of Kubra, A \& Murat, E (2016) (8) study which pointed out at a statistically significant relationship between practicing the cellular recreation and experience of viewing the nature.

Table (5) shows: a statistically significant differences in the (Physical Fitness, Escaping from Personal, Psychic \& Social Pressures) between the team and individual sports player in favor of the team sports players where the value of calculated
(T) is greater than its tabular value at (0.05) level. This is due to the nature of the practiced activity done collectively and consequently the desire of players in competing fairly with each other which results in developing the physical fitness and providing opportunities to overcome the abundance of pressures affecting them which cause them a state of tension and discharge the hidden reactions.

There are also nonstatistically significant differences in (Learning, Independence \& Leadership, Performance, Incentives, Humanitarian Relations \& Viewing the Nature) dimensions between the individual and team sports players where the value of calculated $(\mathrm{T})$ is less than its tabular value at (0.05) level. This is because practicing the activities make the players gain knowledge related to nature of the activity in terns if legal knowledge; also the correct methods used for the practice and identifying the consequence of practicing this activity on the body organs. 
Also, some players' preference to practice the recreational activities independently as the consequence of enjoying the individual performance and the non-agreement on specifying the practice time.

Figure

(2)

shows

statistically significant differences in the daily leisure size variable for individual and team sports players among (Less than 3 hours), From (3-6) Years and (6) Hours and longer in favor of (6) hours and longer where value of calculated (F) value is greater than its tabular value at (0.05) level. This is due the increase in their leisure time which results in increasing the need to practice various activities which reduce the burdens and pressures imposed on them and improving their quality of life and opportunities for rest through practicing recreational activities which achieve a better standard of living. These results match LUO, L \& CHIA, H (2005) (9) study which showed that practicing the recreational activities contributes in achieving happiness.
-Figure(3) shows a statistically significant differences in the Practicing Activities During Leisure Time for individual and team sports players between the Social, Cultural, Artistic Activities and the Public Service in favor of the Cultural Activity where the calculated $(F)$ value is greater than its tabular value at $(0.05)$ level. This is because the individual and team players enjoy spending their leisure time in practicing the mental and cultural activities so that equilibrium takes place among them from both the physical and mental aspects. This match with what stated by AlSamnodi \& Others (2016) that the individual which depends in his work on the physical effort, can benefit from the mental recreation (3: 30) The results of Meryem, $A$ \& Ece, D (2016) (10) study showed that the research sample prefer practicing the social and cultural activities.

\section{Conclusions:}

Based on the research results and within the limits of the research sample and its procedure, the researcher provides the following conclusions: 
- The recreational experience scale consists of (37) items distributed over

dimensions.

-The recreational experience scale is characterized by high validity and steadiness coefficients. This scale is good to identify the recreational experience level for the individual and team sports for players in Arab Republic of Egypt.

-The high level of the recreational experience level for the individual and team sports players implies the importance of practicing the recreational activities in the leisure time.

-The older and more experienced players practice the recreational activities experience to get a better health and a more active life.

-The individual and team sports players realize achieving personality equilibrium from the physical and mental aspects.

Recommendations:

Based on the research results, the researcher submits the following recommendations:

-Utilizing the current scale in identifying the recreational experience level for individual and teamsports players.

-The continuity of practicing the recreational activities in parallel with training and competition periods.

- Implementing the recreational experience scale on various categories of the Arabic society.

- Performing scientific research over the recreational experience and its influence on some psychological and social variables.

\section{Sources:}

\section{1-Al-Hamahmi, M. \&Abd}

Alziz,A: Recreation between Theory \& Implementation, AlKitab Center for Publication, Cairo (2009).

2-AL-Samnodi, M \& Others: Recreational Education, Shajara Al-Dor Library, AlMansora (2017).

3- AL-Samnodi, M \& Others: Sports Recreation Input, Shajara Al-Dor Library, Al-Mansora (2017).

4- Chih, $\mathbf{Y}$ and Feng, $\mathrm{H}$ : Influence of the Sports Tourism Attractiveness, Motivation and Experience on Revisit Intentions, Journal of Social Sciences \& Humanities 
Research, Volume 2, Issue 1, 2016.

5- Jeroen, $S$ and Steven, $V$ : Social stratification in adults' sports participation from a time-trend perspective Results from a 40-year household study, European Journal for Sport and Society, Vol 8, No (1/2), Pg 31-44, 2011

6- Kadouri, M,: The Sports Recreational Awareness for the Activities Supervisors in the Secondary Stage in Iraqi Republic, A Master Degree, Faculty of physical education, Al-Mansoura University (2015).

7- Kübra, A and Murat, E: Outdoor recreation motivations and nature experiences: the case of Eskişehir, 2013. mmv.boku.ac.at/. https://www.researchgate.net/ 8- Kübra, A and Murat, E: Outdoor recreation participants' motivations, experiences and vacation activity preferences, Journal of Vacation Marketing,Pg1-13, 2016.

9- Luo, L and Chia-H: Personality ,Leisure Experiences and Happiness, Journal of Happiness Studies, Vol 5,Pg 325-342, 2005. .

\section{0- Meryem, $A$ and Ece, D:} An Assessment of Students' Recreation Participation, USChina Education Review B, Vol. 6, No. 8,Pg 467480, August 2016.

\section{1- Solaiman, H. \& Saeid N:}

The students trends towards leisure time (Comparison Study) between male and female students of work camps in Education Ministry, AlRafedaine Magazine for Sportal Sciences, Vol. 10, Mosul (2004).

12- Talba, M: The recreational psychology \& leisure time, Cairo, Islamic Graphic (2010). 